\title{
PARA ALÉM DOS FEMINISMOS: UMA EXPERIÊNCIA COMPARADA ENTRE GUINÉ-BISSAU E BRASIL
}

\author{
Angela Figueiredo \\ Universidade Federal do Recôncavo da Bahia, Cachoeira, Bahia, Brasil \\ Patrícia Godinho Gomes \\ Universidade Federal da Bahia, Salvador, Bahia, Brasil
}

Resumo: Embora tenham suas especificidades - geográficas, demográficas, políticas, econômicas, étnicas e raciais, tanto o Brasil quanto a Guiné-Bissau são ex-colônias portuguesas e apresentam-se como duas realidades sociais em que as mulheres negras, etnicamente diferenciadas e racializadas, elaboram um novo tipo de feminismo a partir de suas relações com ações coletivas dos seus grupos de pertença na reivindicação dos próprios direitos. Referindo-se à América Latina, Lugones (2008) demonstrou como a colonialidade do poder, resultante da experiência e da hierarquia racial da colonização, significou também uma colonialidade de gênero, mas, em que medida é também uma realidade para o contexto africano? Como procuramos demonstrar, o próprio conceito de raça e, consequentemente, de racismo, assumem dinâmicas diferenciadas nas duas sociedades. E o uso do conceito de gênero parece ser mais importante para pensar como as desigualdades se estruturam no Brasil, se comparado à experiência nos países africanos, particularmente na Guiné-Bissau. Nosso objetivo é analisar a experiência do "feminismo negro" nos dois países, numa perspectiva comparada. Buscamos compreender em que medida essas duas realidades apresentam cenários similares no que tange às lutas ideológicas, políticas e sociais das mulheres. Palavras-chave: Feminismo; Mulher negra; Mulher africana; Gênero; Diferença.

Embora as experiências emancipatórias de mulheres guineenses remontem ao período pré-colonial (Philip HAVIK, 1995), é apenas entre os anos 1960 e 1970, no âmbito da resistência anticolonial, que emergem as bases do movimento feminino politizado, no quadro da luta armada. Para além da luta contra o colonialismo, os objetivos do movimento em construção era a efetiva emancipação, a demanda por educação formal e a conscientização das mulheres, em particular as das áreas rurais.

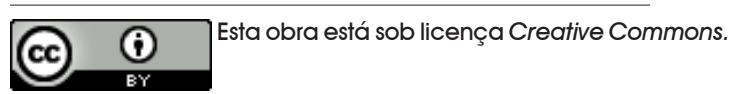


Ainda que as mulheres constituíssem a maioria da população' e a sua participação no processo de independência fosse um fato objetivo e imprescindível, a criação da União Democrática das Mulheres da Guiné e de Cabo Verde - UDEMU - na vizinha Guiné-Conacri, em 1961, não contou, na verdade, com a participação da maioria das mulheres guineenses. Boa parte delas, sobretudo as que se encontravam estabelecidas nas mais remotas comunidades rurais, acabaram por ficar à margem da organização feminina do Partido Africano da Independência da Guiné e Cabo Verde - PAIGC, a mesma que supostamente tinha sido criada para responder aos seus anseios.

As mulheres demonstraram uma reconhecida capacidade em se implicar em ações em prol da restauração e da preservação da liberdade confiscada durante a experiência colonial (Jean O'BARR, 1984; Stephanie URDANG, 1984; 2013). Nesse sentido, tornava-se necessário desenvolver um campo intelectual autônomo de análise e de reflexão que permitisse@s intelectuais african@s um comprometimento mais direto com as realidades sociais africanas.

Sendo a Guiné-Bissau um país essencialmente rural, onde o poder colonial tinha utilizado as tensões entre os povos e os conflitos sociais entre crioulos e outras categorias sociais para interesses próprios, a posição das mulheres na sociedade estava estreitamente ligada ao contexto social ao qual pertenciam e às relações estabelecidas com as instituições do poder colonial - embora a posição das mulheres fosse fundamentalmente de subalternidade.

Nesse caso, tratou-se de uma dupla colonização das mulheres, seja através das estruturas coloniais de opressão, seja por meio das estruturas patriarcais opressivas, que, na visão de Amílcar Cabral, significava uma profunda necessidade de repensar as estruturas sociais, as relações de gênero e as relações étnicas na Guiné-Bissau, a partir da desconstrução colonial, econômica e política, capaz de romper com os modelos teóricos e epistemológicos existentes (Amílcar CABRAL, 1976; Cláudio FURTADO, 2014).

A partir de uma perspectiva transcultural (Oyeronké OYEWÙMÍ, 2005), e buscando novos pressupostos teóricos dos sujeitos femininos provenientes de diferentes contextos socioculturais, Judith Butler (2003) propõe questionarmos sobre até que ponto os feminismos e as categorias conceituais de gênero são aplicáveis às realidades com diferentes lógicas culturais? Não obstante, é necessário destacar as importantes contribuições das teorias feministas ocidentais na construção social do gênero.

Nos países africanos o debate acadêmico chamou a atenção para o impacto do colonialismo e a existência de outras formas de estratificação (lfi AMADIUME, 1987; Oyeronké OYEWÙMÍ, 2005; Paul Tiyambe ZELEZA, 2005). Significa, portanto, que uma análise de gênero não pode prescindir do contexto social específico e formas de hierarquia existentes. A noção da "dupla colonização" perpetrada pelas ideologias colonial e patriarcal, no caso das sociedades africanas, de forma geral, e na sociedade guineense em particular e no caso brasileiro, a noção de dupla ou de tripla opressão, tornaram-se conceitos-chave nos discursos pós-coloniais e feministas a partir dos anos de $1980^{2}$.

O processo histórico de colonização no Brasil, a subordinação e, muitas vezes, a

\footnotetext{
${ }^{1}$ De acordo com os censos de 1991 e de 2009 (Peter KARIBE-MENDY; Richard LOBBAN, 2013, p. 423), as mulheres constituem a maioria da população da Guiné-Bissau (52\%) em todas as regiões e são a maioria em termos da população economicamente ativa (56\%). No entanto, apesar da preponderância numérica e do papel econômico e social que jogam na sociedade, a posição das mulheres guineenses reflete a condição geral das mulheres a nível mais global: limitado acesso aos postos políticos, às instancias legais, à educação e às oportunidades econômicas.

${ }^{2}$ Mary Castro (1992), em "Alquimia das categorias sociais na produção de sujeitos políticos", busca compreender a desigualdade social em sua tripla dimensão: de gênero, raça e classe.
} 
insubordinação das mulheres negras, já foram desenvolvidos em diferentes trabalhos (Sonia Maria GIACOMINI, 1988; Silvana de BISPO, 2011 ; Claudia PONS, 2012). Muitas denúncias foram realizadas pelo movimento de mulheres negras e pelos trabalhos escritos pelas mulheres de $\operatorname{cor}^{3}$, se assim podemos definir o campo dos estudos de gênero e raça no Brasil que, de acordo com Sandra Azeredo (1994) e Kia Lilly Caldwell (2000), é um campo de pesquisa majoritariamente formado por mulheres negras.

As denúncias se dirigiam às condições de vida das mulheres negras, à invisibilização das mulheres negras no processo histórico e às narrativas hegemônicas sobre a formação da sociedade brasileira, bem como sobre a hipersexualização do corpo feminino negro. A esse respeito, o trabalho de Lélia Gonzalez (1983) é significativo em sua capacidade de demonstrar os estereótipos construídos sobre as mulheres negras, que se consolidam em três figuras emblemáticas: a ama de leite, a mulata e a empregada doméstica.

Do ponto de vista da produção acadêmica nos últimos anos, no Brasil, o conceito de interseccionalidade, tal como formulado pela feminista afro-americana Kimberlé Crenshaw (2002), tem sido utilizado com bastante entusiasmo para analisar a relação entre as diferentes categorias de opressão. A autora destaca a "forma pela qual o racismo, o patriarcalismo, a opressão de classe e outros sistemas discriminatórios criam desigualdades básicas que estruturam as posições relativas de mulheres, raças, etnias, classes e outras" (CRENSHAW, 2002, p. 177). A interseccionalidade, de certo modo, responde às críticas feitas por algumas autoras. Patricia Hill Collins (2000), por exemplo, considera que a noção de dupla ou tripla discriminação não dá conta das interconexões entre formas distintas de opressão, que se sobrepõem e se influenciam mutuamente.

Entretanto, o conceito de interseccionalidade tem sofrido críticas. Danielle Kergoat (2010) considera que a perspectiva definida por Crenshaw torna a posição social demasiadamente fixa,

[...] e, de maneira geral, a ideia de intersecção, dificulta pensar uma relação de dominação móvel e historicamente determinada [...]. Em outros termos, a interseccionalidade é um instrumento de análise que coloca as relações em posições fixas, que divide as mobilizações em setores, exatamente da mesma maneira pela qual o discurso dominante naturaliza e enquadra os sujeitos em identidades previamente definidas. (KERGOAT, 2010, p. 93).

Nesse sentido, a crítica de Kergoat (2010) se dirige inclusive à imagem visual do conceito, pois considera a metáfora de "círculo" e "espiral" mais eficaz na compreensão dos fenômenos sociais, a partir de uma perspectiva materialista, histórica e dinâmica, propondo as noções de consubstancialidade e coextensividade. A tese defendida por ela é de que as relações sociais são relações antagônicas entre dois grupos. As relações sociais são consubstanciais, pois formam um nó que não pode ser desatado no nível das práticas sociais, mas apenas na perspectiva da análise sociológica; e são coextensivas uma vez que, ao se desenvolverem, as relações sociais de classe, gênero e "raça" se reproduzem e se coproduzem mutuamente (KERGOAT, 2010).

Da perspectiva do feminismo negro brasileiro, como dito anteriormente, o conceito de interseccionalidade tem sido uma ferramenta teórica e política útil de análise, pois catalisa uma demanda já existente da denúncia e da ação dos movimentos de mulheres negras em torno de uma análise mais acurada acerca da realidade vivida, uma relação complexa que não pode ser resumida apenas às dimensões de gênero, raça e classe, ainda que sejam categorias importantes de análise. Do ponto de vista da visualização do conceito, a imagem do entrecruzamento de avenidas, proposta por Crenshaw (2002), é

\footnotetext{
${ }^{3} \mathrm{~A}$ expressão refere-se a uma produção de feministas que compartilham da experiência colonial.
} 
muito mais próxima do nosso referencial, pois uma intersecção é também uma encruzilhada - espaço de referência significativo para as religiões afro-brasileiras. A encruzilhada é um lugar de encontro, mas é também um espaço de múltiplas saídas, lugares, caminhos, ruas e estradas. A encruzilhada é um dos importantes locais onde se coloca oferenda para Exú, o mensageiro entre os diferentes mundos no candomblé. Nesse sentido, utilizando dos nossos referenciais locais e acentuando o dinamismo de tal posição, diríamos que o conceito de interseccionalidade não apenas refere-se a uma possibilidade de entrecruzamentos de categorias de opressão, mas também de possibilidades de emancipação. Quer dizer, os movimentos sociais têm cada vez mais necessidade de incorporar uma perspectiva interseccional na agenda política.

Do ponto de vista da reflexão africana, particularmente no caso guineense, o conceito de interseccionalidade não goza da mesma popularidade, visto que as diferenças nem sempre se exprimem em termos de desigualdade, e nem sempre são sinônimos de hierarquia ou de opressão, como destacado por Adriana Piscitelli (2008). Nesse sentido, cabe indagar se as diferenças sociais remetem sempre a um processo de discriminação e de opressão ou se, pelo contrário, remetem à diversidade, ao igualitarismo e a formas mais democráticas de participação política.

A partir dessa reflexão teórica, e procurando uma validade metodológica ancorada nas realidades históricas e sociais distintas, nosso objetivo é o de analisar o contexto da Guiné-Bissau e do Brasil numa perspectiva comparada. Apesar de suas especificidades geográficas, demográficas, políticas, econômicas, étnicas e raciais -, tanto o Brasil quanto a Guiné-Bissau são ex-colônias portuguesas e se apresentam como duas realidades sociais em que as mulheres negras, etnicamente diferenciadas e racializadas, elaboram um novo tipo de feminismo a partir de suas relações com ações coletivas dos seus grupos de pertença na reivindicação dos próprios direitos. No entanto, buscaremos compreender em que medida essas duas realidades apresentam cenários similares, no que tange às lutas ideológicas, políticas e sociais das mulheres.

\section{Analisando contextos e experiências e afinando conceitos nos dois países}

Baseadas em críticas já existentes acerca da pluralidade do feminismo, procuramos neste texto demonstrar os diferentes aspectos dos feminismos negros no Brasil e dos feminismos africanos, lançando mão de uma perspectiva política e ideológica baseada na reflexão de que os indivíduos, as etnias ou os grupos sociais, independentemente do "gênero", constroem interesses diferenciados, sendo suas reivindicações fundamentalmente demandas por reconhecimento.

Aqui é importante destacar, ainda que brevemente, a clássica distinção entre políticas de redistribuição e de reconhecimento, proposta por Nancy Fraser (2006). De acordo com essa abordagem, a redistribuição estaria relacionada aos aspectos econômicos, principalmente envolvendo a classe social, enquanto que a política de reconhecimento envolveria as questões de diferença/identidade. Em contextos fortemente marcados por discriminação são exigidas políticas de reconhecimento; entretanto, a autora considera que isso não precisa e não deve ser feito a partir de políticas de identidade. No contexto brasileiro há uma melhor aceitação das políticas de redistribuição frente às políticas de identidade - ver o caso da reserva de vagas para estudantes oriundos de escolas públicas em comparação com a reserva de vagas para negros nas universidades.

Nas dinâmicas identitárias, a autoidentificação ou o autorreconhecimento dos sujeitos ou grupos vitimizados/excluídos/oprimidos são determinantes. Segundo Celi Regina 
Jardim Pinto (2008), o reconhecimento como autorreconhecimento é essencial para a construção do sujeito da ação na luta social. Só existe o dominado contra a dominação, se este se reconhecer como tal. Não há feminismo antes da feminista, assim como não há paridade participativa antes do sujeito autorreconhecido como igual (PINTO, 2008).

No caso guineense, embora as complexidades étnico-sociais e as estruturas patriarcais de poder tenham, em parte, obstaculizado a organização e a institucionalização de um movimento feminista - ainda que, em termos discursivos, tenha sido recorrente a referência à posição das mulheres na sociedade e à necessidade da sua emancipação política -, todavia, existe um autorreconhecimento da importância do papel desempenhado pelas mulheres na construção do Estado independente. Entretanto, esse autorreconhecimento não foi acompanhado por uma agenda política em termos de promoção da equidade de gênero. Muitas mulheres guineenses constataram o não cumprimento das promessas em termos da promoção do seu estatuto socioeconômico e político no período pósindependência. Sobre tal propósito, é interessante o testemunho de Ana Lopes, miliciana mobilizada em 1973, em Koundara, no leste da Guiné-Bissau, zona fronteiriça com a vizinha República da Guiné, já na fase final da luta de libertação:

Nós, as mulheres, trabalhamos muito e quando chega a hora de atribuir cargos políiticos e de responsabilidade a nível do Estado chamam sempre os homens para os ocupar [...]. Em relação às campanhas eleitorais, quem trabalha? São as mulheres! São elas a dar a força e a trabalhar para garantir a vitória aos homens, mas quando chega o momento de dirigir, são sempre os homens. Pergunto-me porque as mulheres não comandam? Isto é algo que me faz pensar muito! ${ }^{4}$

É claro que um esforço para pensar comparativamente, a partir da experiência dos feminismos em contextos tão distintos, ainda que compartilhando da experiência colonial, sem uma tradição de perspectivas comparativas previamente estabelecidas, é muito desafiador. Referindo-se à América Latina, Maria Lugones (2008) demonstrou particularmente como a colonialidade do poder, resultante da experiência e da hierarquia racial da colonização, significou também uma colonialidade de gênero. Mas, em que medida é também uma realidade para o contexto africano? Como procuraremos demonstrar mais adiante, o próprio conceito de raça e, consequentemente, do racismo, assumem dinâmicas diferenciadas nas duas sociedades. O uso do conceito de gênero parece ser mais importante para pensar como as desigualdades se estruturam no Brasil, se comparado às experiência s africanas, particularmente na Guiné-Bissau.

A questão da diferença parece central para a reflexão sobre os feminismos negros e africanos. Em primeiro lugar, queremos destacar as diferenças e semelhanças internas entre o movimento de mulheres e o(s) feminismo(s) negro(s), uma questão ainda importante para o Brasil. Muitas mulheres ativistas rejeitam o rótulo de feministas, preferindo identificar-se como ativistas ou simplesmente se declaram integrantes dos movimentos de mulheres, visto que ainda associam tal movimento ao feminismo de mulheres brancas de classe média. Além disso, no caso brasileiro, de acordo com Lélia Gonzalez, o feminismo branco não só omitiu a diferença racial, como compartilhou da crença na democracia racial (GONZALEZ, apud Sueli CARNEIRO, 2011 , p. 3). Ainda que saibamos hoje da existência de vários feminismos, esta identificação do feminismo com o seu momento inicial ainda permanece nas representações de algumas lideranças e integrantes do movimento de mulheres.

Cristiano Rodrigues (2013) observa que há um reconhecimento de algumas mulheres negras como participantes fundamentais na formatação dos movimentos Negro e Feminista

${ }^{4}$ Entrevista concedida por Ana Lopes a Patrícia Godinho Gomes em Bissau (Guiné-Bissau), em 14 de outubro de 2009. 
- Luiza Bairros, Beatriz Nascimento, Lélia Gonzalez, Sueli Carneiro, Edna Roland, Jurema Werneck, Nilza Iraci, Matilde Ribeiro, entre outras, que nos anos de 1980-1990 contribuíram intensamente para o debate e a visualização das desigualdades sofridas pelas mulheres negras. Todavia, o número de participantes da luta do movimento de mulheres é infinitamente maior.

A esse respeito, Claudia Pons (2012) analisa as tensões existentes no estabelecimento dos limites de identidade entre o movimento de mulheres e o movimento feminista, baseandose nos depoimentos de mulheres ativistas por ela entrevistadas. A autora recupera as diferentes perspectivas e agendas entre o movimento feminista e o movimento de mulheres, e lança mão de uma proposta interpretativa proposta por Maxine Molyneux, na qual busca um lugar para a diferença entre os dois termos, ao estabelecer uma distinção entre o interesse de gênero - que seria uma espécie de agenda comum com vistas a uma crítica ao patriarcado e à hegemonia masculina - consequentemente, esta perspectiva busca uma emancipação feminina, e os interesses mais genéricos - o interesse das mulheres que seriam baseados na diferença das demandas específicas do contexto social das mulheres. Por fim, Pons (2012) argumenta em prol de uma distinção entre o movimento de mulheres e o movimento feminista, ainda que considere o movimento de mulheres num sentido bastante amplo.

Na definição proposta por Jurema Werneck, e destacada por Pons, a categoria movimento de mulheres negras abriga uma identidade política fortemente construída por estas mulheres, a partir da reivindicação do passado histórico de luta em comum. A autora é orientada pela compreensão de que "o enfrentamento ao racismo é fundamental e prioritário", pois se constitui no "principal fator de produção de desigualdades seja entre mulheres e homens, seja entre mulheres". Desigualdades acentuadas pela força do sexismo e do heterossexismo (WERNECK, 2007, p. 1, apud PONS, 2012, p. 239).

Sem querer estabelecer critérios distintivos/identificadores entre os dois grupos, ao que parece, os estudos têm apontado para o fato de que o movimento de mulheres ainda reflete uma demanda quotidiana através de uma agenda em que reivindica o direito a questões fundamentais, tais como saúde, educação e moradia. Enquanto o movimento feminista, mesmo aquele composto por mulheres negras, questiona as bases do racismo, do sexismo e do patriarcado e demandam por direitos iguais aos dos homens e das mulheres brancas; por sua vez, a geração mais jovem incluiu na agenda a liberdade sexual, entre outros aspectos. Nesse sentido, há questões emergenciais que são prioritárias para as mulheres negras, independente dessas supostas diferenciações, como aquelas relacionadas ao direito à vida, pois muitas mulheres querem ter o direito de criar os seus filhos, diante dos constantes atos de violência policial, que terminam em assassinato de jovens negros.

Todavia, se aceitarmos a proposta de Ochy Curiel, sobre a importância de incluir outras experiências na narrativa sobre o surgimento do feminismo,

Aunque como concepto el feminismo nace en la primera ola en este contexto como una propuesta que sintetiza las luchas de las mujeres en un lugar y en un tiempo determinado, si entendemos el feminismo como toda lucha de mujeres que se oponen al patriarcado, tendríamos que construir su genealogía considerando la historia de muchas mujeres en muchos lugares-tiempos. Este es para mí uno de los principales gestos éticos y políticos de descolonización en el feminismo: retomar distintas historias, poco o casi nunca contadas. (Ochy CURIEL, 2009, p. 1).

A narrativa sobre a insurgência do feminismo negro tem considerado que a origem do movimento estaria associada a uma dupla ruptura: a) com o movimento feminista e b) com o movimento negro. Estudos mais recentes têm contestado tal perspectiva. Sherie M. 
Randolph (2015) faz uma análise da trajetória pessoal, política e ativista de Florynce Kennedy. De acordo com a autora, os principais aspectos da agenda feminista já eram assumidos por Flor desde os anos 1960. Do mesmo modo, ressalta a relação de Flor com o movimento afro-americano, demostrando, dessa maneira, que o movimento feminista afroamericano não é originário de uma ruptura, mas de uma circulação de ideias. De acordo com a autora, o movimento emerge exatamente dos interstícios de/ou entre os dois movimentos. Caberia aqui indagar em que medida essa narrativa hegemônica não pressupõe uma subordinação do feminismo negro ao feminismo branco?

Silvana de Bispo (2011) retrata a articulação do movimento de mulheres na Bahia, inicialmente através do Grupo de Mulheres do Movimento Negro Unificado (GM), para fazer frente às práticas sexistas dentro da entidade. De acordo com a autora, somente em 1995, após sérias divergências, as mulheres do GM decidiram por se retirar do MNU. Já as articulações que deram origem ao GELEDÉS em São Paulo e ao CRIOULA no Rio de Janeiro seguem caminhos diferentes. No caso da Bahia, houve inicialmente um rearranjo, em termos de prioridade das agendas, circulação de ideias e da permanência das mulheres negras em ambos os movimentos. O que aponta para uma contradição na origem do movimento de mulheres negras, posto que a ideia de ruptura com o movimento social negro não se verificou inicialmente. Em ambos os movimentos, a raça - leia-se também o racismo e a desigualdade racial - continua a ser um fator importante para interpretar também as desigualdades de gênero.

Além disso, ainda precisamos retratar aspectos relativos às continuidades históricas do movimento, como as irmandades femininas negras dos séculos XVII e XIX, como é o caso da Irmandade da Boa Morte ${ }^{5}$, e da participação social e política das mães-de-santo como um contraponto emancipatório importante em uma sociedade patriarcal que atribui um papel de subordinação às mulheres. No livro A cidade das mulheres, Ruth Landes (2002) chama a atenção para a importância das mulheres no candomblé, devido ao exercício da liderança feminina no culto, em um contexto social patriarcal, onde as lideranças políticas e religiosas eram exercidas por homens. Landes também destaca o comportamento social de algumas mulheres negras no período, que não correspondia aos padrões morais e de subordinação atribuídos às mulheres.

Lélia Gonzalez já havia chamado atenção para a importância da raça e, de acordo com a autora,

[...] o movimento de mulheres tem sido analisado a partir de três vertentes: a popular, a político-partidária e a feminista [...]. Gonzalez conclui que "[...] nossa inserção no movimento de mulheres deve ser caracterizada como uma quarta vertente, pois nossa 'tomada de consciência' da opressão ocorre, antes de tudo, pelo racial". (GONZALEZ, apud BAIRROS, 2000, p. 363)

Suely Carneiro reafirma esta perspectiva ao considerar que:

[...] o feminismo negro, construído no contexto de sociedades multirraciais, pluriculturais e racistas - como são as sociedades latino-americanas - tem como principal eixo articulador o racismo e seu impacto sobre as relações de gênero, uma vez que ele determina a própria hierarquia de gênero em nossas sociedades. (CARNEIRO, 2011, p. 2).

\footnotetext{
${ }^{5} \mathrm{~A}$ Irmandade da Boa Morte é uma confraria de mulheres negras, integrantes da igreja católica e atuantes no Candomblé, que iniciou suas atividades no século XIX em Salvador, tendo como objetivo inicial contribuir para a compra de alforria de seus irmãos que ainda viviam na condição de escravos. Outro objetivo era oferecer um enterro digno e, por isso mesmo, uma Boa Morte. Todos os anos no mês de agosto é realizada a Festa da Boa Morte em homenagem à Nossa Senhora da Boa Morte, em Cachoeira - Bahia. (Luana Verena Nascimento MACHADO, 2013).
} 
Por fim, a autora sugere que as mulheres negras precisam estar voltadas para duas ações imediatas, ou levar em conta um duplo movimento: de um lado enegrecer o feminismo e, de outro, feminilizar o movimento negro:

Enegrecer o movimento feminista brasileiro tem significado, concretamente, demarcar e instituir na agenda do movimento de mulheres o peso que a questão racial tem na configuração, por exemplo, das políticas demográficas, na caracterização da questão da violência contra a mulher pela introdução do conceito de violência racial como aspecto determinante das formas de violência sofridas por metade da população feminina do país que não é branca; introduzir a discussão sobre as doenças étnicas/ raciais ou as doenças com maior incidência sobre a população negra como questões fundamentais na formulação de políticas públicas na área de saúde; instituir a crítica aos mecanismos de seleção no mercado de trabalho como a "boa aparência", que mantém as desigualdades e os privilégios entre as mulheres brancas e negras. (CARNEIRO, 2011 , p. 3).

Assim, a raça tem sido considerada como um elemento estruturante da sociedade e das relações de gênero na cartografia social na América Latina, e especificamente no Brasil. Ainda que, para as novas gerações, a articulação das identidades de gênero e de raça parecem indissociáveis, tanto do ponto de vista do discurso, como através do modo com que a nova geração de mulheres negras pensa e vive o feminismo e a sexualidade.

No caso da Guiné-Bissau, a maioria das mulheres, embora pratique o feminismo de várias formas - primeiramente através dos movimentos sociais de luta pelos direitos femininos, empreendedorismo e das lutas pela participação política--, elas não vislumbram um debate interno, no sentido de uma consciência feminista, tal como acontece no mundo ocidental e no contexto brasileiro, ou seja, as mulheres guineenses são feministas e praticam o feminismo sem saberem que o são.

Isso vai ao encontro do que defende Chimamanda Ngosi Adichie (2014) em Sejamos todos feministas, quando fala da experiência da própria avó que ousou desafiar as decisões dos homens da família quanto ao seu futuro. E essa é precisamente a experiência de várias mulheres guineenses: contrastam as decisões dos maridos, dizem "não" ao que julgam não se adequar às próprias exigências, chegando a se separarem, sem estarem submetidas às decisões das famílias ${ }^{6}$. Isso se tornou possível também graças a uma autonomia progressivamente adquirida através das atividades econômicas desenvolvidas por mulheres e que permitem, em muitos casos, significativa autonomia financeira e, consequente, poder de decisão.

À luz do que foi dito, no caso guineense, não nos parece que se possa fazer uma distinção semelhante àquela proposta pelas mulheres negras brasileiras, uma distinção entre movimento de mulheres e o feminismo negro. Possivelmente, trata-se de ir, tal como nos referimos no nosso título, para além do conceito de feminismo e das formas de apropriação desse conceito, ou, como sugere Curiel (2009), a respeito da América-Latina, é preciso ampliar e descolonizar o conceito de feminismo.

Descolonizar para las feministas latinoamericanas y caribeñas supondrá superar el binarismo entre teoría y práctica pues le potenciaría para poder generar teorizaciones distintas, particulares, significativas que se han hecho en la región, que mucho puede aportar a realmente descentrar el sujeto euronorcéntrico y la subalternidad que el mismo feminismo latinoamericano reproduce en su interior, sino seguiremos analizando nuestras experiencias con los ojos imperiales, con la conciencia planetaria de Europea

${ }^{6}$ Embora no caso de divórcios pesem as práticas consuetudinárias das respetivas etnias de pertença, sendo em alguns casos processos bastante complexos.

916 Estudos Feministas, Florianópolis, 24(3): 909-927, setembro-dezembro/2016 
y Norteamericana que definen al resto del mundo como lo OTRO incivilizado y feministas europeas y norteamericanas implicará reconocer estas experiencias teóricas y políticas como parte del acervo y la genealogía feminista, pues solo así será posible un feminismo transnacional basado en la complicidad y solidaridad de muchas de las feministas que compartimos los mismos proyectos políticos de emancipación. (CURIEL, 2009, p. 7).

Outro aspecto importante da comparação é a centralidade da raça, no caso brasileiro com relação à Guiné-Bissau. O significado de "raça", para os africanos vivendo em África, não é o mesmo para os afrodescendentes do Novo Mundo. Nesse sentido, é fundamentalmente importante compreender que a colonização, a exploração, o racismo e as relações estabelecidas entre os africanos e os brancos foram diferentes daquelas produzidas na experiência colonial fora de África, e qual o papel dessas diferenças na percepção do racismo e nas práticas discriminatórias (Kwame Antony APPIAH, 2010).

De acordo com Tcherno Djaló (2012), a mestiçagem constituiu um fator de consolidação e desenvolvimento desses territórios no contexto colonial, uma vez que os mestiços estabeleceram relações privilegiadas com o poder colonial, tendo acesso às vantagens que 0 regime oferecia ${ }^{7}$. Desse modo, estabeleceram-se hierarquias e desigualdades entre as várias realidades socioculturais na Guiné-Bissau, exacerbando as diferenças socioculturais num contexto de luta pelo poder político. A principal forma de desigualdade social e política seria assim definida a partir das relações entre crioulos considerados "burmedjus" (indivíduos de pele mais clara), grupo constituído pela elite local e associado à modernidade, aos valores civilizatórios europeus e visto como "superior", em oposição ao resto da população nativa. Assim sendo, o preconceito deve ser pensado e compreendido como um fenômeno profundamente relacionado às próprias possibilidades de acesso ao exercício da cidadania no contexto do Estado colonial ${ }^{8}$.

Na Guiné-Bissau e em muitos outros contextos africanos, com algumas poucas exceções como é o caso sul-africano, onde a elite dominante era branca, o racismo, tal como experimentado nos contextos diaspóricos, não foi necessariamente o elemento estruturante da hierarquia de gênero, mas a etnicidade e os modelos patriarcais subjacentes.

A maioria dos dirigentes do PAIGC - Partido Africano da Independência da Guiné e Cabo Verde - não adotou a visão de gênero emancipacionista de Amílcar Cabral, que acreditava na necessidade de repensar as estruturas sociais, as relações de gênero e as relações étnicas na Guiné-Bissau, a partir da dupla desconstrução colonial, econômica e política, capaz de romper com os modelos teóricos e epistemológicos existentes (CABRAL, 1976; FURTADO, 2014). Os homens do partido acabaram por reproduzir os mesmos

\footnotetext{
${ }^{7}$ Ainda que o tema da mestiçagem seja muito importante para pensar o Brasil, optamos neste texto por enfatizar a mestiçagem apenas no caso da Guiné-Bissau, para a melhor compreensão das hierarquias étnicas de lá.

${ }^{8}$ Nesse ponto não há convergência entre as autoras. Ainda que a hierarquia não seja estruturada em termos raciais, branco $X$ negro, há uma lógica hierárquica entre os grupos étnicos que remete ao período colonial. Por outro lado, não se compreende a formulação do conceito de raça com base em seu princípio biológico ou fenotípico, pois o processo de racialização diz sobre o lugar que se ocupa nas relações desiguais de poder. No caso guineense, embora seja possível considerar que houve uma "racialização" da sociedade no período colonial, tendo em conta a hierarquização estabelecida e a evidente hegemonia da elite crioula dominante (ao serviço do poder colonial português), essa realidade deve ser distinguida da experiência brasileira. No caso guineense, as relações de poder estabelecidas, embora assimétricas e fundamentalmente de subordinação dos africanos ao poder colonial, contaram com importantes elementos como as línguas nacionais e o substrato cultural das diferentes realidades socioculturais, muitas vezes determinantes em termos de negociação de poder. Não houve apenas a oposição entre brancos e negros e isso ficou evidente no período pós-colonial, com a retirada formal dos europeus (para mais detalhes veja-se Carlos LOPES, 1989 p. 243-266).
} 
comportamentos patriarcais, hierárquicos, sociais e familiares com suas companheiras de luta (Aliou LY, 2014).

A liderança do PAIGC, entre os quais Amílcar Cabral, pertencia à burguesia de Bissau, descendentes dos cabo-verdianos, e que tiveram acesso às vantagens oferecidas pelo poder colonial instituído, em particular à formação e a emprego nas estruturas do Estado colonial; os mesmos que no contexto do Estado independente iriam assumir a liderança (Peter Karibe MENDY, 1999).

Para os considerados "sujeitos coloniais" ou "indígenas", excluídos do exercício da cidadania, originários dos diferentes grupos étnicos e que constituíam a maioria da população, as possibilidades educativas e de ascensão social eram limitadas. Puderam usufruir de pouco mais do que uma instrução de base pelas missões católicas no período colonial, e foram marginalizados no processo de construção nacional aviado após 1975. Essa realidade iria provocar, nas décadas sucessivas, fraturas sociais e tensões políticas, com repercussões importantes não apenas para a sociedade de forma geral, mas também nas relações de gênero e nas relações entre as próprias mulheres, particularmente entre as mulheres rurais, as das tabankas (mulheres de áreas rurais) e as mulheres das cidades, criando hierarquias e cristalizando posições.

Portanto, no caso da Guiné-Bissau, as estruturas hierárquicas de poder se dão tanto na articulação de classe e de gênero, em que o colonialismo teve um impacto importante, mas, sobretudo, em termos da dicotomia cidade-campo, que acaba por refletir as diferenças culturais e étnicas. As mulheres que protagonizaram e se apropriaram do discurso emancipatório do movimento de libertação eram majoritariamente do meio urbano, e que acessaram as instituições de formação asseguradas pelo Estado colonial. Por outro lado, os movimentos sociais protagonizados pelas mulheres, e que assumimos como práticas feministas, emergiram essencialmente das experiências de mulheres vivendo no mundo rural.

Na Guiné-Bissau, entendemos por "movimento de mulheres" os movimentos sociais de reivindicação de direitos em vários níveis. Em termos de movimento feminista, não nos parece possível identificar um movimento tal como no Brasil, pelas razões apresentadas acima e pelo discurso sobre as diferenças abissais que existem entre os dois países, em termos de acesso à educação e à formação profissional, pois, a maioria das mulheres guineenses não teve acesso à um educação formal e de qualidade.

\section{Conquistas, direitos e a continuidade da luta}

Suely Carneiro (2003) destaca as conquistas alcançadas pelo movimento feminista negro no Brasil e indaga sobre quais seriam os novos aportes. Com o intento de atualizar as respostas, mas, sobretudo, pensar comparativamente as duas realidades em estudo, Carneiro destaca a

[...] Constituição de 1988, que contemplou cerca de $80 \%$ das suas propostas, o que mudou radicalmente o status jurídico das mulheres no Brasil. A Constituição de 1988, entre outros feitos, destituiu o pátrio poder.

[...] Destaca-se, nesse cenário, a criação dos Conselhos da Condição Feminina - órgãos voltados para o desenho de políticas públicas de promoção da igualdade de gênero e combate à discriminação contra as mulheres. A luta contra a violência doméstica e sexual estabeleceu uma mudança de paradigma em relação às questões de público e privado. A violência doméstica tida como algo da dimensão do privado alcança a esfera pública e torna-se objeto de políticas específicas. (CARNEIRO, 2003, p. 117).

Além disso, a autora sublinha a incorporação da temática da raça na saúde e dos direitos reprodutivos na agenda da luta antirracista. Este é um aspecto importante, visto que 
parte das feministas negras são originárias da área de saúde, e iniciaram sua atuação política através da denúncia ao extermínio da população negra, por meio de práticas interventivas de controle da natalidade assumidas pelo governo nos anos de 1980. No que se refere a uma atualização da questão formulada por Carneiro, acerca dos conteúdos aportados pelo feminismo negro na arena política no Brasil, gostaríamos de destacar a criminalização e as medidas contra o feminicídio e o combate à violência contra as mulheres. Assim como, a conquista do direito já assegurado a tod@s@s trabalhador@s doméstic@s, através da PEC 66/2012, sancionada em 01 de junho de 2013, que incluiu os seguintes direitos: seguro-desemprego, indenização em caso de demissões sem justa causa, saláriofamília, adicional noturno, auxílio-creche e seguro contra acidente de trabalho. Vale lembrar que o direito à carteira assinada para@s trabalhador@s doméstic@s somente foi possível em 1972. E em 1988, outros direitos e benefícios foram adquiridos, como por exemplo, férias de trinta dias, licença-maternidade, aposentadoria por invalidez e tempo de serviço, férias com mais de um terço do salário e folgas nos dias de feriados. Assim, a conquista do Fundo de Garantia do Tempo de Serviço (FGTS) e, consequentemente, do seguro desemprego, consiste em uma luta ainda travada pela categoria nos dias de hoje.

Como é sabido por tod@s, o trabalho doméstico ainda é a porta de acesso ao mercado de trabalho por parte de mulheres negras com baixa escolaridade, principalmente originárias da região norte e nordeste do país. Locus privilegiado na análise sobre a permanência de relações escravistas na modernidade, o trabalho doméstico foi visto pela maioriad@s pesquisador@s como uma espécie de não trabalho, uma vez que as regras estabelecidas para essa atividade eram de natureza não contratual, ou seja, trata-se de um trabalho exercido dentro do espaço doméstico, recompensado com baixa remuneração, não gerador de renda conforme o tradicional conceito de geração de renda e com lentas conquistas das leis trabalhistas - já asseguradas a muitas categorias profissionais - por parte das trabalhadoras domésticas.

As pesquisas sobre o tema (Jurema BRITES, 2000; Alda BRITTO DA MOTTA, 1992; Mary CASTRO, 1992) sinalizam para a existência de uma contradição na modernidade, pois o serviço doméstico faz ressurgir o paternalismo e o clientelismo na relação entre as classes empregadora e trabalhadora. De acordo com Brites (2000), essa relação se constitui numa controvérsia, visto que exatamente aquilo que se critica é observado por algumas das profissionais como as vantagens do serviço doméstico frente a outras formas de trabalho.

Como assinalou Paul Gilroy (2001), há uma tendência entre @s analistas a acreditar que a modernidade seja uma etapa superior e absolutamente distinta da escravidão. 0 autor tanto argumenta que não haveria modernidade sem a escravidão, quanto demonstra as diferentes formas de escravidão dentro da modernidade. Nesse sentido, o trabalho doméstico pode ser compreendido não apenas como o resquício das relações escravistas dentro da modernidade, mas como uma relação de contradição ao discurso moderno, uma vez que tal discurso constrói sua narrativa baseado na crença de relações de trabalho contratuais, e não mais através da exploração do trabalho escravo.

Como destacado em outro trabalho, Angela Figueiredo (2014) considera que esses fatores mencionados contribuem, sobremaneira, para que os direitos, mesmo os já existentes, não sejam garantidos à categoria. Por essa razão, homens e mulheres no trabalho doméstico necessitam negociar, mesmo estando em posições desiguais numa estrutura social desigual e hierárquica. Para compreender as dinâmicas existentes nas negociações, é fundamental entender a importância das relações pessoais, dos mecanismos informais de ajuda, de consideração, de respeito e de afeto nas relações estabelecidas por indivíduos que constroem sua identidade como sujeitos através da negação e da invisibilidade. Com relação à execução do trabalho, o serviço doméstico só é visto quando não é realizado; e, 
do ponto de vista de quem efetua o trabalho, a condição de invisibilidade no espaço doméstico é a melhor forma para ser considerada uma boa profissional.

De outro modo, a questão do trabalho doméstico também aparece como um ponto de tensão entre @s que acreditam que esse tipo de trabalho deve ser extinto, visto que recoloca a mulher trabalhadora numa condição de subordinação, e a demanda dos sindicatos das trabalhadoras domésticas reivindicam exatamente a manutenção do trabalho através de melhores condições para executá-lo, além da necessária e urgente garantia do cumprimento dos direitos já assegurados pela lei.

Tendo em conta os propósitos deste texto e, consequentemente, da falta de tempo e de espaço, não abordaremos a importância política, social e simbólica da Marcha da Mulheres Negras, ocorrida em Brasília, em 18 de novembro de 2015, tampouco poderemos abordar a invisibilização de tal acontecimento pela mídia nacional, através da não veiculação de notícias deste importante momento. As demandas da marcha estão contidas na "Carta das Mulheres Negras". Para os propósitos deste texto, apenas mencionaremos algumas delas, tais como: direito à vida e à liberdade; promoção da igualdade racial; direito ao trabalho; direito à educação; direito à justiça; direito à moradia, à terra e à cidade; direito à segurança pública e direito à cultura; e, do que nos parece verdadeiramente mais subversivo, do ponto de vista de um novo pacto social: em marcha, nós mulheres negras em Brasília, exigimos um novo projeto civilizatório.

Da mesma forma como não poderemos enfrentar o discurso sobre as conquistas das mulheres africanas, nomeadamente no quadro da "Década da Mulher Africana 20102020", do "Protocolo de Banjul sobre os direitos da Mulher", adotado em 2003, que procurou incentivar os Estados africanos a incluírem nas próprias leis nacionais mecanismos de proteção e de garantia dos direitos das mulheres e da equidade de gênero e, ainda, as lutas levadas adiante pela "Rede das Mulheres Parlamentares da Guiné-Bissau" o que hoje constitui uma importante plataforma política das reivindicações das mulheres guineenses, em nível nacional e regional da África ocidental?

O movimento feminista na Guiné-Bissau, tal como o compreendemos, nasceu a partir de uma luta anticolonial e de um processo revolucionário conduzidos contra o poder colonial português, em que as mulheres tiveram uma participação significativa. $O$ discurso emancipatório oficial procurou promover a imagem das mulheres guineenses, mostrando a sua centralidade no processo de independência e na sociedade em geral. Seguindo os objetivos do movimento de libertação, as principais reivindicações do movimento feminista se concentraram na busca de melhores condições sociais e econômicas para as mulheres, como a luta contra determinadas práticas culturais ancestrais, tais como os casamentos precoces e as circuncisões. No âmbito da formação ideológica, foi significativa a influência do marxismo na formação política das mulheres e dos homens, o que contribuiu em boa medida para tornar ainda mais evidente os comportamentos sexistas e patriarcais dos homens do "partido".

No caso guineense, poder-se-ia usar o paradigma da empregada doméstica como elemento de análise da condição de marginalização da mulher, não por ser negra, uma vez que não ocorre o problema da "cor", tal como no Brasil, mas por ser da tabanka, da aldeia, do mundo rural, portanto, considerada inferior, sem instrução e sem possibilidades de aspirações e de ascensão social, como anteriormente referido na nossa discussão. Mais uma vez encontramos uma relação com os estigmas criados pela ideologia colonial, fortemente absorvidos e interiorizados na sociedade local, de forma geral, sobretudo pelas elites instruídas.

${ }^{9}$ Veja-se a este propósito Gomes (2013). 
Na Guiné-Bissau, o tema da emancipação feminina se destacou, pelo menos em termos discursivos, como uma das prioridades das políticas sociais do governo pósindependência, o que refletiu, de certo modo, na continuidade de uma das diretrizes do PAIGC no período da libertação, não se tratando de uma política de concessão do governo. Nessa perspectiva, e num esforço de implementação prática dos princípios de emancipação e igualdade de gênero, é que se dá a reorganização do movimento de mulheres, através da reorganização da UDEMU e do movimento feminino de forma mais geral.

Não obstante, temos os importantes resultados alcançados durante a luta de libertação, o nível de transformação social verificado foi substancialmente desigual nas diferentes regiões do país. Ainda menos, o fato de essas regiões terem sido formalmente "libertadas" das garras do colonialismo pressupôs a eliminação das práticas coloniais perpetuadas. Assim, por exemplo, paralelamente a situações em que as mulheres assumiam posições de destaque em vários níveis do aparelho estatal, verificavam-se situações de discriminação com base no gênero. Essa realidade exigia, antes de mais nada, uma análise dos processos históricos na Guiné-Bissau em toda a sua complexidade ${ }^{10}$.

O debate político que as mulheres têm levado a cabo nos últimos anos, seja em nível das instituições políticas, dos partidos políticos ou das organizações da sociedade civil, conduziram à instituição de uma Agenda Comum das Mulheres, cujos temas se concentram fundamentalmente na questão da participação política das mulheres e na reivindicação de quotas de $40 \%$ para as mulheres nas estruturas de direção dos partidos políticos ${ }^{11}$.

A esse respeito, a recente criação da Plataforma Política das Mulheres guineenses (PPM) se traduziu numa importante conquista em termos do percurso emancipatório. Constituída em 2008, graças ao apoio técnico e financeiro das Organizações das Nações Unidas (ONU), tal Plataforma é composta por mulheres dos diferentes partidos políticos, por organizações femininas e por organizações da Sociedade Civil (sindicatos, ONGs, organizações religiosas e organizações da comunicação social). Em particular, a PPM assumiu um papel relevante durante as eleições gerais de 2008-2009, graças à definição de uma Agenda Comum para as Mulheres, amplamente divulgada e assumida pelas diversas forças políticas e, graças ao estabelecimento de um Plano Estratégico Operacional 2013-2016 "Educar, participar e transformar" e sua base de ação, lançada em agosto de 2013.

A interrupção da ordem constitucional por via do golpe de Estado de 12 de abril de 2012 conduziu a um agravamento da já fragilizada condição sociopolítica e econômica do país, fundamentalmente dependente das ajudas externas ${ }^{12}$. As conquistas que vinham sendo operadas relativamente às questões femininas, nomeadamente no domínio legislativo (aprovação em 2011 da Lei contra a Mutilação Genital Feminina) e os esforços políticoinstitucionais realizados a favor da prática da equidade de gênero, não encontraram o devido apoio nem espaço na Agenda Política das novas autoridades do país. Não obstante, constatou-se durante o período de transição uma mobilização política da Sociedade Civil guineense sem precedentes, envolvendo sobretudo jovens e mulheres ${ }^{13}$.

\footnotetext{
${ }^{10}$ Dentre os mais destacados trabalhos sobre a luta anticolonial e o processo de independência na GuinéBissau, vejam-se em particular Basil Davison (1968) e Mustafah Dhada (1993).

11 Plataforma Política das Mulheres da Guiné-Bissau (PPM-GB) - Plano Estratégico Operacional 2013-2016 "Educar, participar e transformar", Bissau, agosto de 2013.

12 Sobre o golpe de 12 de abril de 2012 e das questões e problemáticas concernentes à implementação da Reforma do Setor de Segurança (RSS), veja-se: International Crisis Group, "La réforme du secteur de la sécurité en Guinée-Bissau": une occasion a saisir, Briefing Afrique, n¹09, Dakar/Bruxelas, 19 de março de 2015. Disponível em: www.crisisgroup.org. Acesso em: 19/06/2015.

${ }^{13}$ A iniciativa da criação do blog do Movimento Ação Cidadã - MAC, em 2012, inscreve-se nesse quadro. O referido blog, constituído por jovens guineenses estabelecidos no país e na diáspora, promoveu vários seminários e encontros durante o período de transição e de debates políticos entre os candidatos às eleições
} 
A PPM poderá vir a constituir a base de mobilização e de organização das mulheres guineenses no sentido da reivindicação e da negociação da sua posição e da sua função em nível do poder político estabelecido, se guiada pelo espírito democrático e pela prática da inclusão. Nessa base, torna-se imprescindível concretizar os objetivos estabelecidos no Plano Estratégico Operacional da Plataforma, fundamentados na sua visão, nos seus princípios orientadores e na sua missão.

Por outro lado, é necessário se referir à importância que as associações e os movimentos femininos têm representado para importantes mudanças socioculturais em

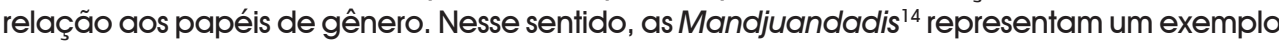
significativo de formas de resistência à discriminação, exercendo um impacto considerável em suas próprias comunidades. Através de estratégias de denúncia pública da opressão, a que muitas vezes estão sujeitas, acabam por influenciar outras mulheres, levando-as a reclamar pelos seus direitos sociais, econômicos e políticos. Através de suas ações, esses agrupamentos de mulheres desencadeiam importantes processos de mudança social que favorecem a promoção dos direitos das meninas e das mulheres por gerações.

\section{Comentários Finais}

Ao longo da nossa reflexão, procuramos compreender, através de uma análise comparada, alguns caminhos percorridos pelos movimentos feministas negros no Brasil e na Guiné-Bissau, a partir da problematização do conceito de gênero e da sua aplicação, especialmente, no contexto guineense. A categorização da "mulher", inicialmente presente nos discursos feministas como um grupo homogêneo e bioanatomicamente determinado, constituiu entrave para as análises de gênero, sobretudo em sociedades que haviam sido submetidas à colonização, como nos exemplos que procuramos debater neste texto.

Recuperamos, através do nosso diálogo que, sendo o gênero uma categoria histórica e socialmente construída, ela não pode ser analisada da mesma forma em tempos e espaços diferentes, ou em sociedades que apresentam caraterísticas sócio-históricas diversas; portanto, é necessário analisar as várias dinâmicas e atores locais (agregados, grupos, organizações etc.) que tomaram e tomam parte no processo de construção das identidades de gênero. Portanto, sendo uma construção social, o gênero acaba por ser também um fenômeno cultural. Consequentemente, é lógico assumir a possibilidade de que, em algumas sociedades, o gênero não necessariamente se constituiu ou se constitui como elemento estruturante da sociedade.

O lugar onde as mulheres negras se forjaram e foram forjadas nas sociedades periféricas multirraciais ou multiétnicas, sendo subalternizadas e protagonizando resistências, remete para dois períodos históricos distintos: aquele relativamente recente, de austera subalternização; e um outro período milenar, marcado por um papel de centralidade social (especialmente nas sociedades africanas). Particularmente, procuramos discutir algumas questões consideradas centrais que refletem a subalternização das mulheres negras, do lado de cá e de lá do Atlântico na contemporaneidade, ou num diálogo sul-sul.

legislativas e presidenciais de 2013. Mesmo depois das eleições políticas, o MAC tem organizado diversos encontros e seminários com estudantes, associações de mulheres e comunidades rurais para debater questões ligadas aos conflitos, à instabilidade e ao exercício da cidadania ativa na Guiné-Bissau e questões de gênero (para aprofundamento, veja-se: acaocidada2012.blogspot.com/).

${ }^{14}$ As mandjuandadis são grupos (redes) de solidariedade e de convivência social que funcionam na base da classe etária, de interesses comuns e de acordo com as normas pré-definidas e aceitas por todos os membros. São várias as formas de ajuda e apoios que existem no interior das mandjuandadis, desde a celebração de festas, casamentos, cerimônias, apoios em caso de doença, investimento em negócios, pequenos créditos. Esse tipo de rede existe tanto nas cidades como nos campos (GODINHO GOMES, 2012). 
No caso brasileiro, a colonização pressupôs, sobretudo, o controle do corpo das mulheres e o domínio de seu destino e, com isso, o controle de seu futuro e da sua posição na sociedade. Foi dentro dessa realidade global que as mulheres negras no Brasil tiveram que se "reconstruir", numa posição de absoluta subalternização. Foi nesse contexto específico que tiveram que construir a própria identidade como mulher e brasileira negra, de origem africana.

No caso guineense, e seguindo a tendência africana, as mulheres procuraram resgatar a própria identidade numa dupla luta, a anticolonial e a antipatriarcal. No entanto, a evidente "ausência" das mulheres na produção intelectual e no discurso político determinou, entre outros fatores (como o baixo nível de escolaridade), a ausência de um movimento feminista bem estruturado e organizado, um fenômeno ainda incipiente. Entretanto, se consideramos a perspectiva teórica de descolonização do feminismo e de sua narrativa hegemônica, teremos que incluir outras experiências e superar o binarismo entre teoria e prática.

Mais do que uma conclusão, o nosso propósito neste momento é chamar atenção para a necessidade de ampliar a comparação entre a experiência do movimento de mulheres e dos feminismos negro e africanos no Brasil e na Guiné-Bissau, com o objetivo de entender quais as diferenças e semelhanças entre os mesmos e em que medida os problemas enfrentados pelas mulheres negras e africanas podem estabelecer um elo e, quiçá, uma agenda em comum. Desde o nosso primeiro diálogo ficou claro que esta seria uma tarefa desafiadora em função do pouco espaço de tempo e da ausência de uma reflexão comparativa anteriormente estabelecida. Todavia, foi possível delinear, embora preliminarmente, os pressupostos de base para uma discussão mais ampla e articulada sobre formas alternativas da construção da ideia de feminismos, na Guiné-Bissau e no Brasil, procurando um contraponto à visão das mulheres como indivíduos "trans-históricos", excluídos do processo de desenvolvimento.

\section{Referências}

ADICHIE, Chimamanda Ngosi. Sejamos todos feministas. São Paulo: Companhia das Letras, 2014.

AMADIUME, Ifi. Male daughters, female husbands: gender and sex in an African society. London: New Jersey: Zed Books, 1987.

"Theorizing matriarchy in Africa: kinship ideologies and systems in Africa and Europe". In: OYEWÙMí, Oyèrónké (Ed.). African gender studies: a reader. Hampshire, Inglaterra: Palgrave Macmillan, 2005, p. 83-98.

APPIAH, Kwame Antony. Na casa de meu pai. A África na filosofia e na história. Rio de Janeiro: Contraponto, 2010.

AZEREDO, Sandra. "Teorizando sobre genero e relações raciais". Revista Estudos Feministas, Florianópolis, Número Especial, $2^{\circ}$ sem, p. 203-216, 1994.

BISPO, Silvana de. Feminismo em debate: Reflexão sobre as organizações de mulheres negras em Salvador (1978-1979). 2011. Dissertação (Mestrado em Estudos Interdisciplinares sobre Mulher, Gênero e Feminismo - NEIM) - Faculdade de Filosofia e Ciências Humanas da Universidade Federal da Bahia (UFBA), Salvador.

BRITES, Jurema. Afeto, desigualdade, rebeldia: bastidores do serviço doméstico. 2000. Tese (Doutorado em Antropologia) - Universidade Federal do Rio Grande do Sul, Porto Alegre.

BRITTO DA MOTTA, Alda. "Emprego doméstico: revendo o novo". Caderno CRH, n. 16, p. 31 49, jan.-jun. 1992. 
BUTLER, Judith. Problemas de gênero: feminismo e subversão da identidade. Rio de Janeiro: Civilização, 2003.

CABRAL, Amílcar. "A cultura nacional". In: ANDRADE, Mário de (Org.). Obras escolhidas de Amílcar Cabral - A arma da teoria. Unidade e luta. Lisboa, Portugal: Serra Nova, vol. I, 1976, p. 221-247.

CALDWELL, Kia Lilly. "Fronteiras da diferença". Revista Estudos Feministas, Florianópolis, v. 8 , n. 2, p. 91-108, 2000.

CARNEIRO, Suely. Enegrecer o feminismo: a situação da mulher negra na América latina a partir de uma perspectiva de gênero. 2011 . Disponível em: http://disciplinas.stoa.usp.br/ pluginfile.php/375003/mod_resource/content/0/Carneiro_Feminismo\%20negro.pdf. Acesso em: 18/01/2016.

"Mulheres em movimento". Estudos Avançados, São Paulo, v. 17, n. 49, p. 117-132, set./dez. de 2003. Disponível em: http://www.scielo.br/pdf/ea/v1 7n49/18400.pdf. Acesso em: 18/01/2016.

CARTA DAS MULHERES NEGRAS. Disponível em: http://www.geledes.org.br/carta-das-mulheresnegras-2015/. Acesso em: 20/02/2016.

CASTRO, Mary Garcia. "Alquimia das categorias sociais na produção de sujeitos políticos: Genero, Raça e Geração entre líderes do Sindicato de Trabalhadores Domésticos em Salvador". Estudos Feministas, Florianópolis, n. 0, p. 57-73, 1992. Disponível em: https:// periodicos.ufsc.br/index.php/ref/article/view/15801. Acesso em: 26/05/2016.

CURIEL, Ochy. "Descolonizando el feminismo: una perspectiva desde a América Latina y el Caribe", 2009. In: Coordinadora Feminista. Disponível em: http://feministas.org/IMG/pdf/ Ochy_Curiel.pdf. Acesso em: 20/01/2016.

COLLINS, Patricia Hill. The black feminist thought. London: Routledge, 2000.

CRENSHAW, Kimberlé. "Documento para o encontro de especialistas em aspectos da discriminação racial relativos ao gênero". Revista Estudos Feministas, Florianópolis, v. 10, n. 1, p. 171-189, 2002.

DJALO, Tcherno. O mestiço e o poder. Identidades, dominações e resistências na Guiné. Lisboa, Portugal: Nova Vega, 2012.

FIGUEIREDO, Angela. "Pec ou a lei áurea dos tempos modernos? Relações de gênero e cidadania tardia para as trabalhadoras domésticas". In: ASSIS, Gláucia de Oliveira; MINELLA, Luzinete Simões; FUNCK, Susana Bornéo. (Orgs.). Entrelugares e mobilidades: desafios feministas. V. 3. Tubarão, Santa Catarina: Copiart, 2014, p. 289-319.

FRASER, Nancy. "Da redistribuição ao reconhecimento? Dilemas da justiça numa era 'póssocialista'". Trad. de Julio Assis Simões. Cadernos de Campo, São Paulo, n. 14/15, p. 231-239, 2006. Disponível em: http://www.revistas.usp.br/cadernosdecampo/article/ viewFile/50109/54229. Acesso em: 20/06/2015.

FURTADO, Cláudio. "Desafios teóricos e metodológicos nos estudos de África: possibilidades e limites". In: CARVALHO, Maria Rosário; FURTADO, Cláudio; BARBOSA CORREIA Wesley, VINHAS, Wagner (Orgs.). Estudos étnicos e africanos. Revisitando questões teóricas e metodológicas. Salvador: EDUFBA, 2014, p. 19-42.

GIACOMINI, Sonia Maria. Mulher e escrava: uma introdução ao estudo da mulher negra no Brasil. Rio de Janeiro: Vozes, 1988.

GILROY, Paul. O Atlântico negro: modernidade e dupla consciência. São Paulo: Editora 34, 2001.

GODINHO GOMES, Patrícia. "Amilcar Cabral and Guinean women in the fight for emancipation". In: MANJI, Firoze; FLETCHER JR., Bill (Ed.). Claim no easy victories. The legacy of Amilcar Cabral. Dakar: CODESRIA/Daraja Press, 2013, p. 279-294. 
"As mulheres do sector informal. Experiências da Guiné-Bissau". Ciclo de encontros sobre o empreendedorismo, Centro de Recursos de empreendedorismo feminino, Alentejo Central (Portugal), 2012. Disponível em http://www.cisa-as.uevora.pt/empreendedorismo. htm. Acesso em 14/06/2016.

"Sobre a gênese do movimento feminino na Guiné-Bissau: bases e práticas (19611982)". In: GODINHO GOMES, Patrícia; DIOGO, Rosália; DINIZ, Débora; SANTOS, Maria Helena (Orgs.). O que é o feminismo? Cadernos de Ciências Sociais, Maputo, Editora Escolar, 2015, p. 13-46.

"Na senda da luta pela paz e igualdade. O contributo das mulheres guineenses". In. Buala, 2013. Disponível em http://www.buala.org/pt/mukanda/na-senda-da-luta-pelapaz-e-igualdade-o-contributo-das-mulheres-guineenses. Acesso em 12/02/2016.

GONZALEZ, Lélia. "Racismo e sexismo na cultura brasileira". Ciências Sociais Hoje 2, Brasília: Anpocs, p. 223-244, 1983.

HANDEM, Diana Lima. "A mulher e o desenvolvimento". In: HANDEM, Diana Lima; SILVA, Fernando Delfim da (Orgs.). A Guiné-Bissau a caminho do ano 2000. Bissau: Instituto Nacional de Estudos e Pesquisa - INEP, 1989, p. 253-277.

HAVIK, Philip. "Relações de gênero e comércio: estratégias inovadoras de mulheres na Guiné-Bissau". Soronda. Revista de Estudos Guineenses, n. 19, p. 25-36, Jan/1995.

KARIBE-MENDY, Peter; LOBBAN JR., Richard. Historical Dictionary of the Republic of GuineaBissau "Women". 4.ed. Lanham (Maryland): Scarecrow Press, 2013, p. 423-427.

KERGOAT, Danièlle. "Dinâmica e consubstancialidade das relações sociais". Novos Estudos, n. 86, 2010. Disponível em: http://www.scielo.br/scielo.php?script=sci_arttext\&pid=S0101 33002010000100005. Acesso em 12/12/2015.

LANDES, Ruth. A Cidade das Mulheres. Rio de Janeiro: Editora da UFRJ, 2002

LAZREG, Marnia. "Decolonizing feminism". In: OYEWÙMÍ, Oyeronké (Ed.). African gender sudies. A reader, Hampshire, Inglaterra: Palgrave Macmillan, 2005, p. 67-80.

LERMA, Betty Ruth Lozano. "El feminismo no puede ser uno porque las mujeres somos diversas. Aportes para un feminismo negro descolonial desde la esperiencia de las mujeres del Pacífico colombiano". La manzana de la discordia, v. 5, n. 2, p. 7-24, julio-diciembre, 2010.

LOPES, Carlos. "A historicidade da construção nacional na Guiné-Bissau. A questão nacional e a Guiné dita "Portuguesa"." In.: A construção da nação em África. Os exemplos de Angola, Cabo Verde, Guiné-Bissau, Moçambique e S. Tomé e Príncipe, Colóquio INEP, CODESRIA, UNITAR, Bissau, Instituto Nacional de Estudos e Pesquisa), 1989, p. 243-266.

"O papel da pesquisa no processo de desenvolvimento". In: HANDEM, Diana Lima; SILVA, Fernando Delfim da. A Guiné-Bissau a caminho do ano 2000. Bissau: Instituto Nacional de Estudos e Pesquisa - INEP, 1989, p. 329-349.

LUGONES, Maria. "Colonialidade e Genero". Revista Tabula Rasa. Bogotá, Colombia, n. 9, p. 73-101, jul-dez, 2008. Disponível em: http://www.revistatabularasa.org/numero-9/ 05lugones.pdf. Acesso em: 20/02/2016.

LY, Aliou. "Promise and betrayal: women fighters and national liberation in Guinea-Bissau", Feminist Africa, Issue 19, p. 24-42, set. 2014. Disponível em: http://agi.ac.za/journals. Acesso em: 02/03/2016.

MACHADO, Luana Verena Nascimento. Poder feminino e identidade na Irmandade da Boa Morte. 2013. Dissertação (Mestrado em Ciências Sociais, Desigualdades e Desenvolvimento) na Universidade Federal do Recôncavo da Bahia (UFRB), Cachoeira, Bahia, 2013.

MENDY, Karibe. "Amílcar Cabral e a libertação da Guiné-Bissau: contexto, desafios e lições para uma liderança efetiva africana". In: LOPES, Carlos (Org.) Desafios contemporâneos da África. O legado de Amilcar Cabral. São Paulo: UNESP, 1999, p. 15-33. 
MITCHELL, Juliet. La condizione della donna. Torino, Itália: Einaudi, 1972.

MOLYNEUX, Maxine. "¿Movilización sin emancipación? Intereses de la mujer, el Estado y la Revolución: El caso de Nicaragua". Desarrollo y Sociedad, Bogotá, D.C, Universidad de los Andes, n. 13, p. 177-195, enero 1984.

O'BARR, Jean. "African women in politics". In: HAY, Margaret; STITCHER, Sharon (Eds.). African women south of the Sahara. Essex, Massachusetts: Longman, 1984, p. 140-155.

OYEWÙMí, Oyeronké. "Visualizing the body: Western theories and African subjects". In:

(Ed.). African gender sudies. A reader, Hampshire, Inglaterra: Palgrave Macmillan, 2005 , p. 3-21.

"Conceptualizando el género: los fundamentos eurocêntricos de los conceptos feministas y el reto de la epistemologia africana". Africaneando. Revista de actualidad y esperiencias, n. 04, $4^{\circ}$ Trimestre, p. 11-33, 2010. Disponível em: http://www.africaneando. org. Acesso em 13/12/2015.

PINTO, Celi Regina Jardim. "Nota sobre a controvérsia Fraser-Honnoth informada pelo cenário brasileiro". Lua Nova, São Paulo, n. 74, p. 35-58, 2008. Disponível em: http://www.scielo.br/ pdf/In/n74/03.pdf. Acesso em: 30/05/2015

PISCITELLI, Adriana. "Interseccionalidades, categorias e articulação de experiências de migrantes brasileiras". Sociedade e Cultura, v. 11, n. 2, p. 263-274, jul/dez 2008.

PONS, Claudia. Outras Falas: Feminismos na perspectiva de mulheres negras brasileiras. 2012. Tese (Doutorado no Programa de Pós-Graduação em Estudos de Gênero, Mulher e Feminismo - UFBA). Mimeo, Salvador, 2012.

RANDOLPH, Sherie M. Florynce "Flor" Kennedy: the life of a black feminist radical. North Carolina: The University of North Carolina Press, Chapel Hill, 2015.

RODRIGUES, Cristiano Rodrigues. "As Fronteiras entre Raça e Gênero no Ativismo Social Brasileiro". Seminário Internacional Fazendo Gênero 10 (Anais Eletrônicos), Florianópolis, 2013. Disponível em: http://www.fazendogenero.ufsc.br/10/resources/anais/20/ 1384446117 ARQUIVO CristianoRodrigues.pdf. Acesso em 20/12/2015.

SADLIER, J. Darlene. Pós-Colonialismo, feminismo e a escrita das mulheres de cor nos Estados Unidos. Disponível em: http://litcult.net/pos-colonialismo-feminismo-e-a-escrita-demulheres-de-cor-nos-estados-unidos/. Acesso em: 01/02/2016.

URDANG, Stephanie. "Women in contemporary national liberation movements". In: HAY, Margaret; STITCHER, Sharon (Eds.). African women south of the Sahara. Essex: Longman, 1984, p. 156-169.

"But we have to fight twice. Reflections on the contribution of Amilcar Cabral to the liberation of women". In: MANJI, Firoze; FLETCHER JR., Bill (Eds.). Claim no easy victories. The legacy of Amilcar Cabral. Dakar: CODESRIA/Daraja Press, 2013, p. 273-278.

ZELEZA, Paul Tiyambe. "Gender biases in African historiography". In: OYEWÙMí, Oyeronké (Ed.). African gender sudies. A reader. Hampshire, Inglaterra: Palgrave Macmillan, 2005, p. 207-232. 
Beyond Feminisms: a Comparative Experience Between Guinea-Bissau and Brazil Abstract: While considering its geographic, demographic, political and economic, ethnic and racial specificities, both Brazil and the Guinea-Bissau were colonized by the Portuguese, and are presented as two social realities in which black women, ethnically differentiated and racialized, prepare a new kind of feminism from its relations with collective actions of the groups they belong in claiming for their rights. Referring to Latin America, Lugones (2008) demonstrated how the coloniality of power, resulting from experience and racial hierarchy of colonization, also meant a gender coloniality; but to what extent is this also a reality for the African context? As we seek to demonstrate, the concept of race and consequently racism, assume different dynamics in both societies. The use of the concept of gender seems to be more important to consider how inequalities are structured in Brazil, compared to the experience in African countries, particularly in Guinea Bissau. Our goal is to analyze the experience of "black feminism" in both countries in a comparative perspective, and try to understand to what extent these two realities present similar scenarios regarding women's ideological, political and social struggles.

Keywords: Feminism; Black Woman; African Woman; Gender; Difference. 